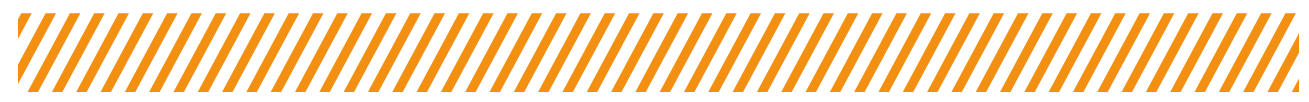

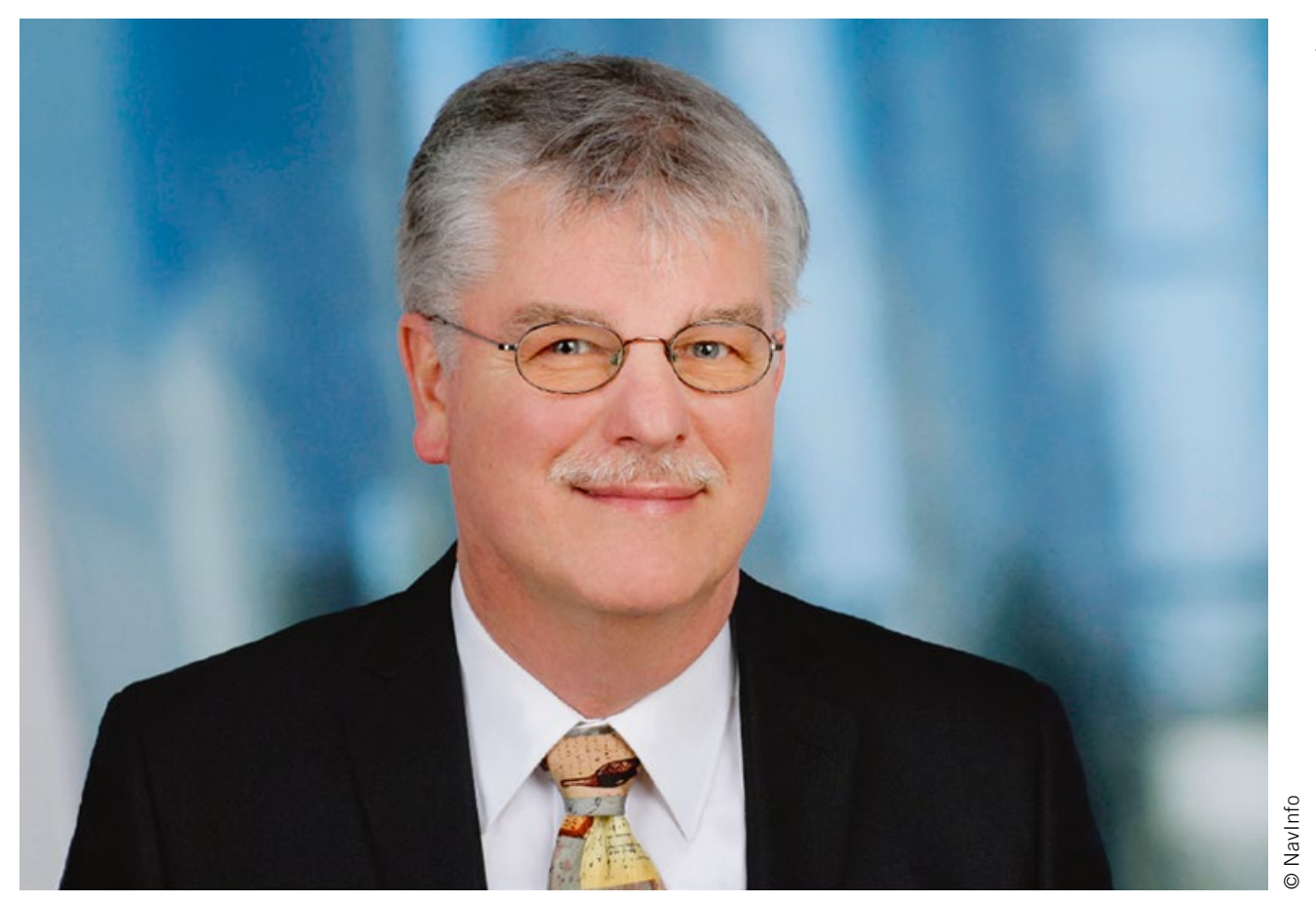

Dr. Volker Sasse

Vice President Navlnfo,

Chairman NDS e.V.

Shanghai (China)

\section{Autonomes Fahren - Vom Individualismus zum Kollektivismus}

Bis heute beherrscht der Individualismus die Autoindustrie. Jeder Fahrzeughersteller forscht für sich an zukunftsweisenden Techniken und eignen Systemen. Je mehr wir uns dem autonomen Fahren zuwenden, desto stärker wird jedoch die Tendenz zum Kollektivismus. Das autonome Fahrzeug bewegt sich nicht mehr autark im Straßennetzwerk. Es beschränkt sich nicht auf die interne Sensorik, sondern kommuniziert mit dem globalen System. Einzelne Fahrzeuge ermitteln mit ihren Sensoren eine Veränderung der Verkehrssituation und geben diese an andere Systeme weiter. Ein Austausch dieser Information mit der Cloud, zum Beispiel die dynamische Aktualisierung einer digitalen Karte, ist unerlässlich, um die Sicherheit und Effektivität des selbstfahrenden Autos im Straßenverkehr zu erhöhen.

Das Teilen von Informationen und die Zusammenführung aller Daten in ein einheitliches, standardisiertes System ist die Voraussetzung für eine sichere Teilhabe selbstfahrender Autos auf den Straßen. Wenn wir demzufolge das autonome Fahren als massentaugliches Fortbewegungsmittel verwirklichen wollen, müssen Auto- und Systemhersteller sowie Informationsverarbeiter ihre Systeme weiter öffnen und in einem Kollektiv zusammenarbeiten. Je größer die Menge unabhängiger, qualitativ hochwertiger Daten-Kollektoren ist, desto höher ist die statistische Wahrscheinlichkeit einer exakten Information. Daher sollten alle Fahrzeuge verschiedener Hersteller ihre aktuelle Information in einer gemeinsamen Cloud speichern, statt nur ihre individuellen Clouds zu bedienen.

In diesem Zusammenhang gibt es keine Alternative zur Standardisierung. Um die Zusammenarbeit von Unternehmen zu fördern, haben wir mit dem „Navigation Data Standard“ e.V. bereits einen ersten Schritt getan: Über 30 Automobilkonzerne, System- und Kartenhersteller weltweit sind Mitglied des Vereins, der einen Standard (NDS) für digitale Karten im Infotainmentsystem etabliert hat. Um den Anforderungen der Zukunft zu begegnen, haben wir den bisherigen internationalen Standard erweitert, um damit die nötigen hochgenauen Karten abbilden zu können. Zudem hat der Verein 2015 das „Open Auto Drive Forum“ (OADF) initiiert, eine Austauschplattform, auf der Unternehmen, Organisationen und Forschungseinrichtungen Lösungen synchronisieren.

Längerfristig handelt es sich um eine Verschiebung vom Individualismus zum Kollektivismus: Wir identifizieren uns nicht mehr als Fahrer eines Fahrzeugs, sondern werden zu Mitfahrern in einem temporären Fortbewegungsmittel, vergleichbar mit der Bahn. Diesen kollektiven Gedanken gilt es auf Seiten aller Beteiligten zu verinnerlichen, damit diese revolutionäre Veränderung unserer (Um-)Welt gelingen kann. 